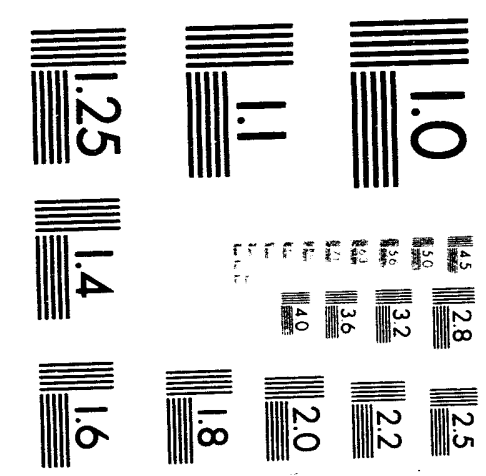



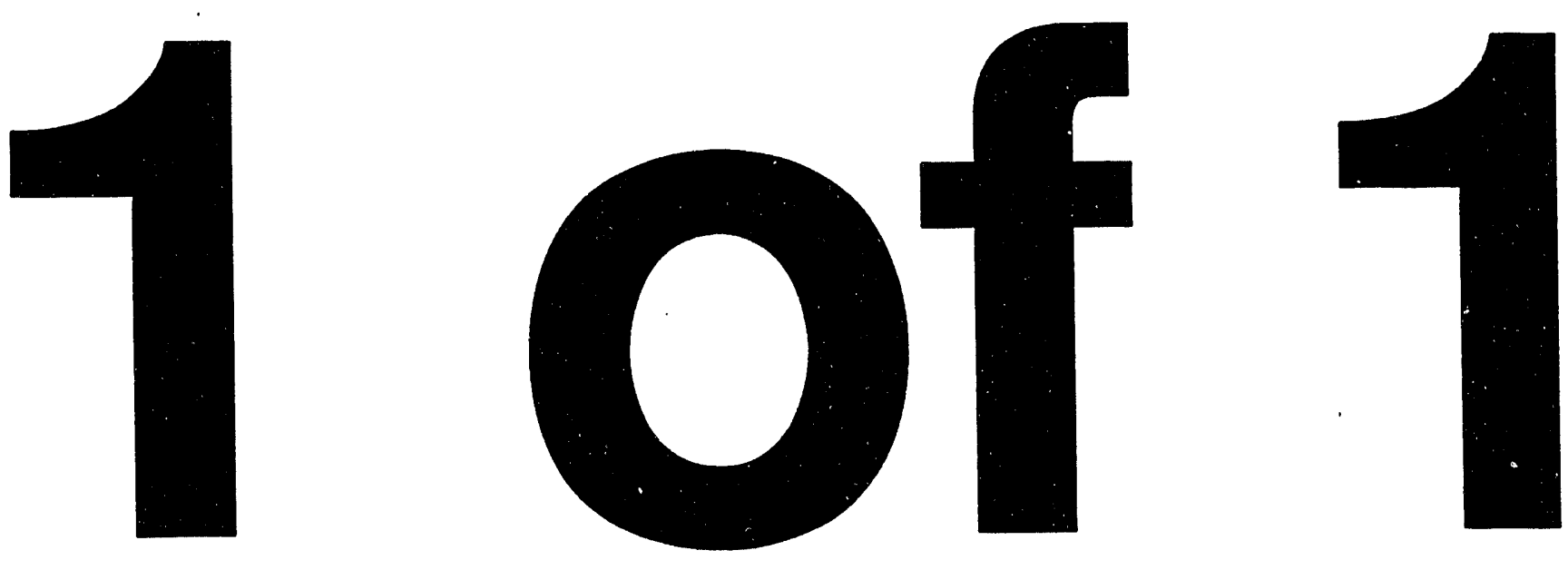


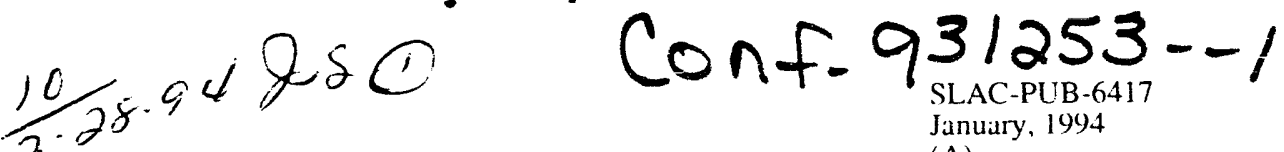

(A)

\section{LINEAR COLLIDERS: THE LAST TEN YEARS AND THE NEXT TEN YEARS}

Rohert H. Sicmann *

Stanford Linear Accelerator Center. Stanford University. Stanford. CA 94309

\section{INTRODLCTION}

Some of the most important discoveries and systematic studies in elementary particle physies have been made at electron-positron colliders. These include the particle physics have heen made at electron-positron colliders. The $\mathrm{C}$-quark and $\tau$-lepton, the discoveries and measurements of the properties of the C-quark and $\tau$-lepton. the studies of B-mesons and gluons. the measurement of the number of light neutrinos. and precision measurements of electroweak parameters. These colliders are such powerful instruments because of the unique center of mass energy and initial quantum numbers. $\mathrm{J}^{\mathrm{PC}}=1^{--}$of $\mathrm{e}^{+} \mathrm{e}^{-}$annihilation, and hackgrounds that are beam-related rather than being an unavoidable part of the total cross section.

Storage rings are limited in center-of-mass energy, E(M. hy synchrotron radiation. The synchrotron radiation energy loss per turn is

$$
\mathrm{U}_{0}=\frac{+\pi \mathrm{r}_{\mathrm{e}}}{3} \mathrm{mc}^{2} \frac{\gamma^{4}}{\rho}
$$

where $\gamma$ is the heam encry in units of rest energy, me2. $r_{0}$ is the classical electron radius, and $\rho$ is the bending radius. The luminosity of a storage ring operating at the beam-beam limit is directly proportional w the thal current. $\mathrm{I}_{\mathrm{T}}$. and heam energy

$$
L=\Sigma \frac{I_{1}}{c} \frac{\gamma}{r_{c} \cdot \beta_{y}^{*}} \text {. }
$$

In this eyuation. $E$ is the heam-beam tunc shitt and $\beta_{\mathrm{v}}^{*}$ is the vertical beta-function at the collision point. Non-resonant cross sections fill as $1 / \gamma^{2}$, and the synchrotron radiation power. $P_{S R}=l_{\Gamma} L_{0}$ ). must increase as $\gamma^{\prime}$ for a constant event rate.

LEP is the largest storage ring in the world: some of its parameters are given in Table 1 . These numbers together with the steep energy dependences of $U_{0}$ and PSR lead to the con lusion that the size and cost of a storage ring collider with a center-ofmass energy much weater than that of LEP would he astronomical!' Linear colliders avoid this energy limit hy not bending the heams. and they extend the potential energy of $\mathrm{a}^{+} \mathrm{e}$ - collisions.

$$
\text { The cross section for producing } \mu \text {-pairs is }
$$

$$
\sigma\left(c^{+} c^{-} \rightarrow \mu^{+} \mu^{-}\right)=\frac{\pi \alpha^{2}}{3\left(m c^{2}\right)^{2}} \frac{1}{\gamma^{2}}
$$

This cross section is 87 th at $F_{(\mathrm{C}}=1 \mathrm{TeV}$. and $\mathrm{L}=10^{33} \mathrm{~cm}^{-2} \mathrm{~s}^{-1}$ at that energy would The 75 give $7.5 \mu$ pare propoto the demanding requirement dominates high energy linear colllider design

\section{* Work supported by the Department of Energy. contract DE-AC13-76SFo(1515.}

Paper Presented at the Sersler Symposium on Beam Physics

\begin{tabular}{|c|c|c|}
\hline Parameter & LEP I & LEP 200 \\
\hline Circumference & \multicolumn{2}{|c|}{$26.659 \mathrm{~m}$} \\
\hline Bending Radius, $\rho$ & \multicolumn{2}{|c|}{$3.1496 \mathrm{~m}$} \\
\hline Total Current, IT & \multicolumn{2}{|c|}{$3.11 \mathrm{~mA}$} \\
\hline Beam Energy, $\mathrm{E}$ & $55 \mathrm{GCV}$ & $95 \mathrm{GCV}$ \\
\hline Energy Loss/Turn, Un & $2611 \mathrm{Me}$ V/turn & $2 . 3 \longdiv { \mathrm { Ge } / \mathrm { tum } }$ \\
\hline Synch. Rad. Power, PSR & $1.56 \mathrm{MW}$ & $13.9 \mathrm{MW}$ \\
\hline Peak RF Voltage & $3601 \mathrm{MV}$ & $2.7 \mathrm{GV}$ \\
\hline Norninal Luminosity & $1.7 \times 10^{31} \mathrm{~cm}^{-2} \mathrm{~s}^{-1}$ & $2.7 \times 10^{3} 1 \mathrm{~cm}^{-2} \mathrm{~s}^{-1}$ \\
\hline
\end{tabular}
Lawrence Berkeley Laboratory

Berkele'v. California. De'cember 6, 1993
Tahle I LEP Parameters 1.2

Linar colliders were first proposed by Maury Tigner in $196.5 .{ }^{3}$ hut the interest in them heared in in the early 198015 when the implications of the energy limitation in them heated up in the cally liom synchrotron radiation was first appre wer than face the corey limit head-on. casier to increase the site of stordge rimg rached to end. and linear colliders would have to he develuned to increase the energy of $\mathrm{a}^{+} \mathrm{e}^{-}$collisions

The y 1980 's was a period of greal enthusidsm about lincar colliders. The SLC had heen spproved and was under comstruction. A quick turn-on and a frest year luminosity of $6 \times 100^{20} \mathrm{~cm}^{-2} \mathrm{~s}^{-1}$ were profeced. ${ }^{4}$ In iddition. perple talked lensely about

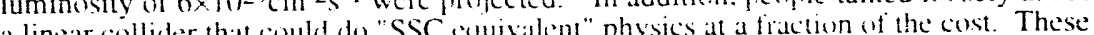
a linear collder he projections were heyond what cotald suppoton a series of acthons that are forming enthusiasm was critical hecause it set into motion da series

the three thrusts in linear collider development. These were: of the SLC that has 1.- The construction, commisstoning:,
established the viability of linear colliders:

- The research and technology develonment aimed at an $\mathrm{E}_{\mathrm{C}} \mathrm{M}=0.5 \mathrm{TEV}$ linear collider that has opened up a new energy range for e+e collisions:

3.- The establishment of the field of advanced accelerators and new particle aceleration techniques that hold out the possihility of $\mathrm{e}^{+} \mathrm{e}^{-}$collisions determining the energy frontier of particle physics in the luture.

Tiaditionally that energy fiontie has helonged to the hitdron colliders where it

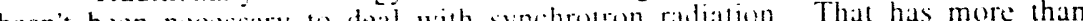

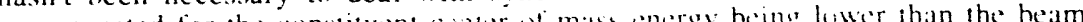
compensated for the constituent conter-or-mass energy heing her than the heam

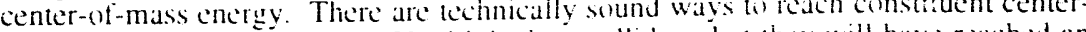
of-mass energies of several TeV with hadron colliders. hin the will have reached an energy where storage rings become impractical after completion of the LHC. An innovation as novel as the linear collider for $\mathrm{e}^{+} \mathrm{e}^{-}$collissions wrould te needed to reach significantly higher energies, and $\mathrm{a}^{+} \mathrm{a}^{-}$linear colliders could determine the energy frontier in the future That will require another slep teyond the $E_{(M)}=0.5 \mathrm{TeV}$ collider that is the present focus of the linear collider communaty. and it is likely to require sucese with some of the directions being pursued hy the advanced accelerator require success

The energy irontier is uncertain and insecure. Despite its outstanding science and technical merit the SSC failed hecause of a combination of politics. cost, and

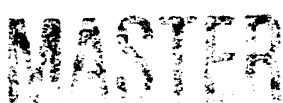


economic climate in the United States. The LHC has not been approved yet, and its construction is not assured. Political and economic issues similar to those for the SSC and LHC are certain to be in the future for linear colliders. To face them one needs to be optimistic that outstanding fare scientilic projects will be supported and that be optimistic that outstanding. large scientilic projects will be supported and that methods for that support will be developed through the expentence with the LHC. large
fusion and space research profe... and the informal iniernational collahorations fusion and space research proje
developing linear collider designs.

\section{THE SLC}

The SLC was intended as a prototype linear collider and as an accelerator for particle physics. These are compatihle because of the large cross section for producing $Z$ 's, $\sigma\left(\mathrm{e}^{+} \mathrm{e}^{-} \rightarrow \mathrm{Z}\right) \approx 30 \mathrm{nh}$. Demonstration of particulars such as small collision spots or high intensities were crucial steps in the development of the SLC hut, by themselves. they are not enough the prove the viahility of linear colliders. That depends on

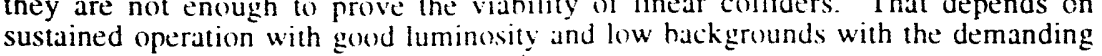
sustained operation with good luminosity and
conditions set by a particle physics experiment.

The SLC had a long. difficul commissioning. It was the first of a new type of accelerator, and despite the hest efforts of the designers, the difficulties of operating it were not appreciated beforehand. Many parameters including peak current, transve!se emittances, and beam sizes were heing pushed into new regimes simultaneously. Linear colliders are like hadron colliders in one way - any mistake made upstream is remembered and emitlance preservation. $\beta$ matching dispersion matching etc are important. This makis many areas simultaneously. Problems in downst can't even he secn until upstream areas are performing reasonably, and collision performance cannot be used to diagnose problems upstream until the downstream is performing reasonably. In many cases new diagnostics and techniques had to be invented and proved to make progress.

The complexity of the SLC is in a new regime also. The enginering standards for performance and reliability are stringeni for a linear collider because there are a large number of components and few of them can fall or he operating out of specification without impictine pertermance This is another facter that made the SLC commisioning difticul New levels of cquipment and heam diagnosics and SLC come the the to be realized and for these to be developed. control were needed. It took time for this to he realized and for these to be developed.
Now they ale part of everyday operation.

SLC commissioning is over, and the SLC is ruming as an accelerator for particle physics and as a prototype linear collider. The day-to-day operation and luminosity improvement programs are shaping many of the ideas ahout future linear colliders.

Table II and Figures 1, 2, and 4 summarize pertormance. There has been steady impro......nt in the average luminosity which reached a peak of $3.5 \times 10^{29}$ $\mathrm{cm}^{-2} \mathrm{~s}^{-1}$ early in the summer of 1993 . The increase from 1992 to 1993 came from the synergy between SLC operation and work on future colliders which are hased on that beams, $\sigma_{x} \gg \sigma_{y}$ to minimize hackgrounds. Emittance preservation and focusing of that beams with high order optical corrections need to he verified experimentally as that beams with high order optical corrections need to he verified experimentally as part of the development of future colliders. The Final Focus Test Beam (FFTB) collaboration was formed to develop and lest a prototype next generation final focus. They need flat beams for thuse lests. and in the process of delivering those beams it SLC performed hetter than expected. Invariant emittances well helow the design value
Table II Typical SLC Parameters for the 1993 Run

\begin{tabular}{|c|c|c|c|}
\hline \multicolumn{2}{|c|}{ Parameter } & \multicolumn{2}{|l|}{ Value } \\
\hline Energy & $\begin{array}{l}\text { at End of Linac } \\
\text { at Interaction Point }\end{array}$ & $\begin{array}{l}46.5 \mathrm{GeV} \\
45.59 \mathrm{GeV} \\
\end{array}$ & $\left(\mathrm{m}_{\mathrm{z}} / 2\right)$ \\
\hline Intensity & $\begin{array}{l}\text { in Damping Rings } \\
\text { at Interaction Point }\end{array}$ & $\begin{array}{l}3.0-3.3 \times 10^{10} \\
2.8-3 .(1) \times 10^{10}\end{array}$ & \\
\hline Polarization & & $0.611-0.64$ & \\
\hline Invariant Emittances & $\begin{array}{l}\text { at End of RTL } \\
\text { at End of Linac }\end{array}$ & $\begin{array}{l}3-4 \times 10^{-5} \mathrm{~m} \\
0.3-0.4 \times 10^{-5} \mathrm{~m} \\
4-5 \times 10^{-5} \mathrm{~m} \\
0.5-\left(0.0 \times 10^{-5} \mathrm{~m}\right.\end{array}$ & $\begin{array}{l}\text { horizontal } \\
\text { vertical } \\
\text { horizontai } \\
\text { verticial }\end{array}$ \\
\hline Beam Size & at Interaction Point & $\begin{array}{l}2.6 \mu \mathrm{m} \\
0.8 \mu \mathrm{m}\end{array}$ & $\begin{array}{l}\text { horizontal } \\
\text { vertical }\end{array}$ \\
\hline RMS Bunch Length & at Interaction Point & $1.0 \mathrm{~mm}$ & \\
\hline RMS Energy Spread & & $\frac{0.3 \%}{120 \mathrm{~Hz}}$ & \\
\hline $\begin{array}{l}\text { Repetition Rate } \\
\text { Luminosity }\end{array}$ & (sec Figure 1) & $\frac{120 \mathrm{~Hz}}{\left(0.2-0.35 \times 10^{30} \mathrm{c}\right.}$ & $m^{-2} s^{-1}$ \\
\hline
\end{tabular}

of $3 \times 10^{-5} \mathrm{~m}$ could be transported down the linat at an intensity of $3 \times 10^{10}$ particles per hunch 5 . SLC ares prevent running with truly tlat beams but elliptical beams are possible. and the reduction in beam are. (Firure 2 ) in 1993 came from that 6

With that beams and the current SLC final focus the minimum vertical heam siz is about $0.8 \mu \mathrm{m}$ (Figure 3 ) and is dominated by a single third-order aherration. the

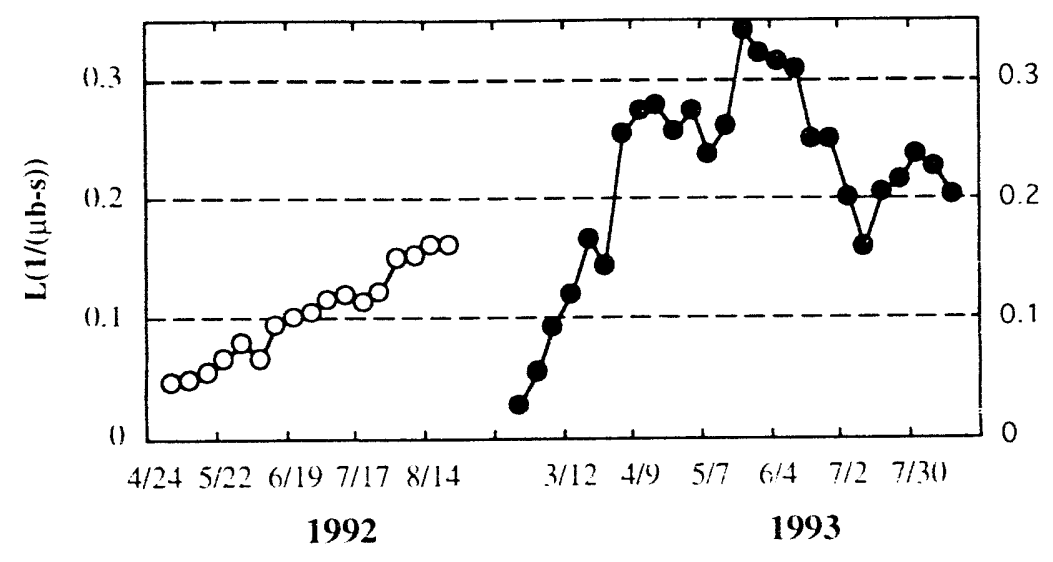

Figure 1. The average SLC luminosity (in units of $1(1)^{301} \mathrm{~cm}^{-2} \mathrm{~s}^{-1}$ ) in 1902 and 1993. 


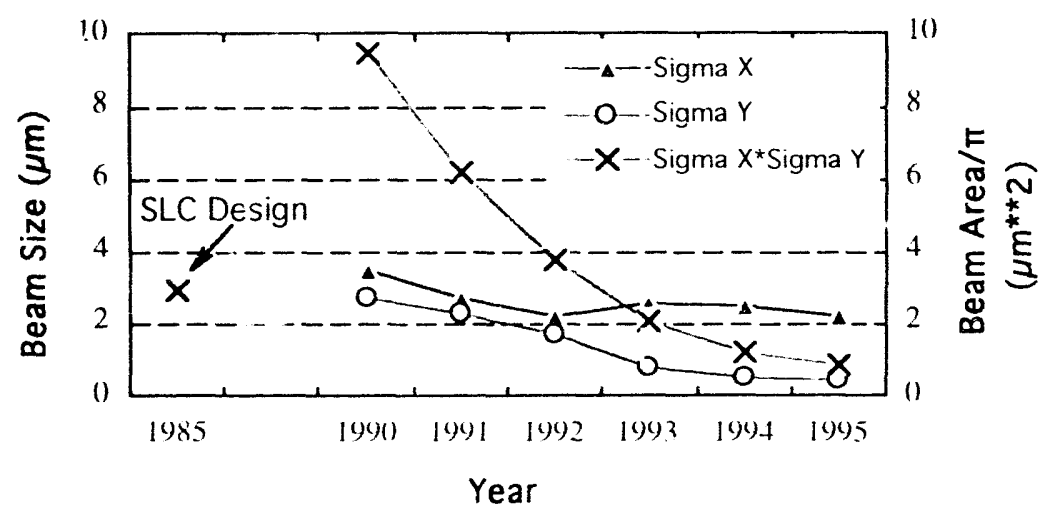

Figure 2. The transwerse heam siess and heam area at the SLC collision point. Past performance and future profections ate shown.

$y^{\prime 2} \delta^{2}$ term in the Hamiltonian (l) in TRANSP(ORT notation). This aherration can he controlled with an additional yiadrupole in the chromatic correction section (CCS). A major SLC upgrade for 1994 is the installation of that quadrupole. some sextupoles to correct geometric aherrations in the final triplet, and additionat optics and diagnostics to did final ficcus tuning.?

The SLC has celied on developments for future colliders in making the performance improvement in 1993 and designing the 1994 upgrade. SLC operation in 1994 will address a vital concern for future colliders - can a highly corrected optical system be diagnosed and tunes last enough and preciscly enough to accommodate the continual changes in the incoming beam from the linac" This development is just one example of the importance of the SLC for future lincar colliders.

The luminesity fell after the peak in the early summer due in part to a heat wave and interruptions to steady running. However. these factors alone cannot explain the reduced lumir.,sity: possible causes include shitts in alignment due to the changing water table and deterioration of the vacuum an a section of the accelerator. These type of problems occur in any accelerator, and leaming w diagnose and fix them quickly is key to good integrated luminosity. Some of the new linal focus diagnostics were motivated hy not heing able to understand the luminusity decrease, and if they prove successtul at quickly identifying problems. SI C oncration will have added even more to the specifications of the diagnostics needed in any future collider

The integrated luminosity is shown in Figure 4 . The SLC has been operating with between for and $86 \%$ uptime and the SLD experiment accumulated over

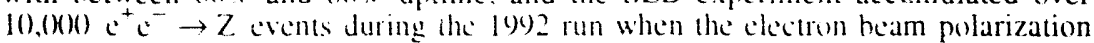
was $P=22 \%$. The first measurement of the kefi-right asymmetry in $Z$ boson production. $A_{1}$. . Was putished hased on thuse dati. ${ }^{8}$ The statistical uncertainty of that measurement is proportional to $1 /\left(P_{1} N_{e r}\right)$ where $N_{e r}$ is the number of events. The polarizatem and number of exents were increased significantly in 1993 to $62 \%$ and 50,000, respective!y, and there should he a ncw. precise medsurement of $A_{I} R$ and the Weinberg Angle based on those data som. The SLC is meeting its goal of being an accelerator for high energy cexperiments

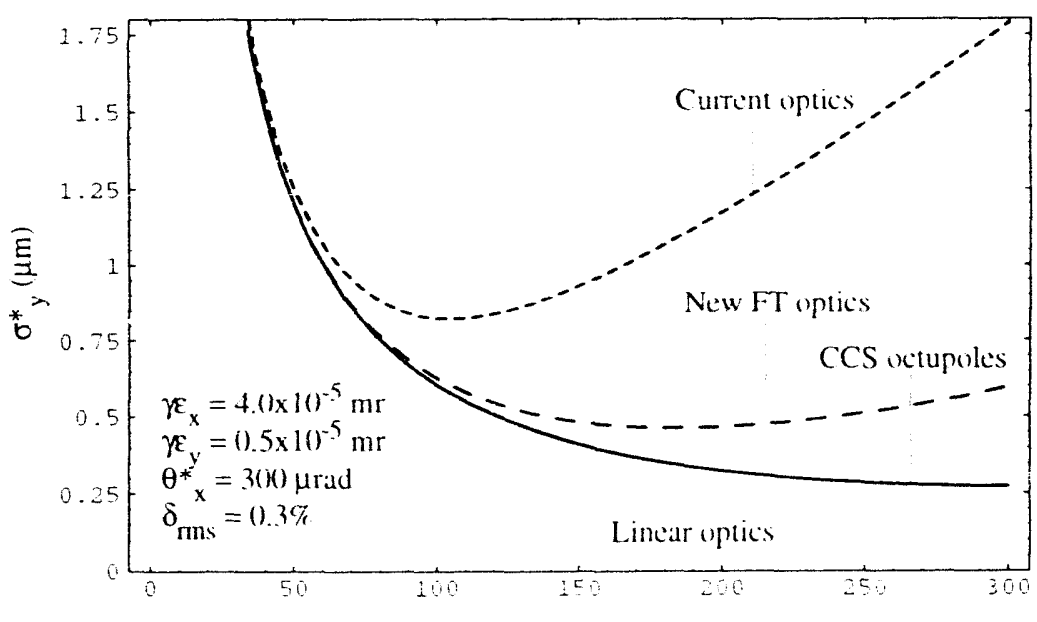

Y Beam Divergence $\left(\theta^{*}\right)$ ( $\mu$ rad)

Figure 3. SLC final focus performance lor the optics used in 1993 ("Current optics") the upgrade being installed for 1994 ("New FT uptics"), and for a possible future improvement ("CCS octupoles").

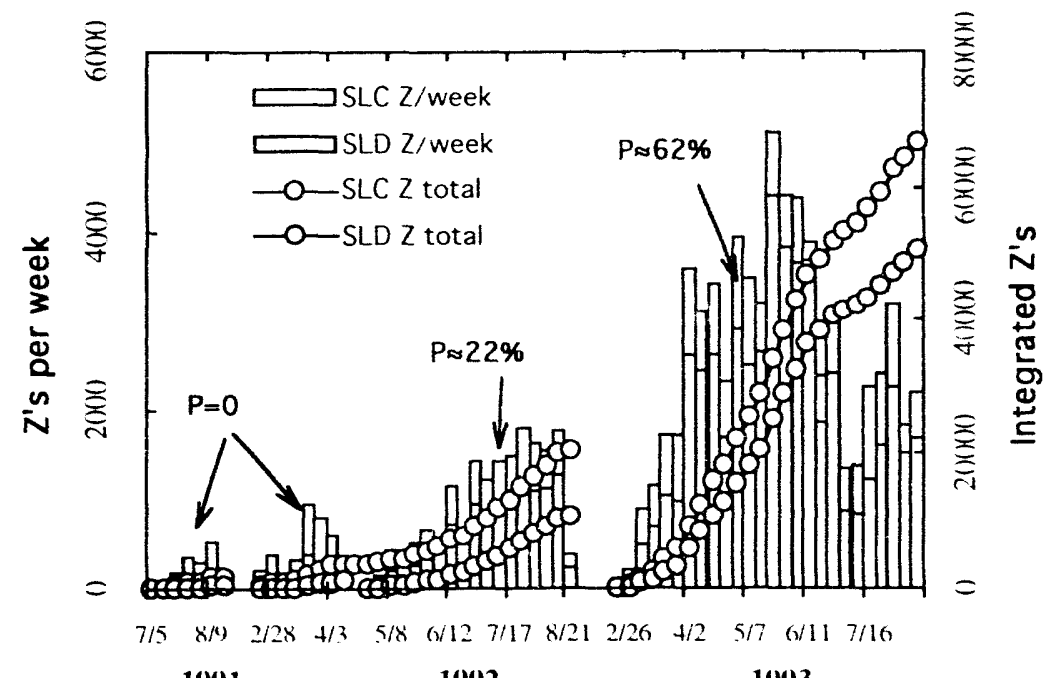

1991

1992

1993

Figure 4. SLC performance for the past three years. The SLC numbers are hased on beam current and spot size measurements from beam-beam deflections. The SLD numbers are the number of $Z$ 's recorded on tape. 
The second major improvement ncaring completion is replacement of the damping ring vacuum chamber. The damping ring bunch length increases due to potential well distortion starting at about $2 \times 10^{10}$ particles per hunch, and the microwave instability theshold is $3 \times 10^{10}$ per bunch. The transverse emittances are increased by potential well distortuon hecause of the following. A longitudinal phase sace rotation is pertormed in the Ring-To-Linac (RTL) transfer line interchanging

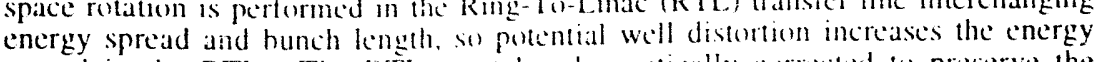
spread in the RTL. The RTL must he chromatically corrected a preserve the transverse emittances," and that correction is not as good and hecomes more sensitive and difficult to maintain against drifts as the energy spread increases.

The microwave instability in the dampeng rings is the present Ste intensity limit. It manifests itself as a relaxation oscillation. The heam radiation damps until the peak current exceeds the iastahility theshold: then the longitudimal phase space blows-up ranidly in -5 syncincotron oscillations, to a peak current that is below brew threste rapid shifts during
mode losses. rotation in the RTL and the phase of injection into the fince. Bunches extracted when the longitudinal phase space is changing rapidly are handled particularly poorly and can he so far off in enerey that the hackgrounds the create trip wift the St. D defector. The only practical way to avoid this has heen to restrict the maximam intensity to near the microwave instability the shold

The present damping ring inupedance is dominated hy masks protecting bellows frum stnchrotron radialtion, transitions hetween different chamber geometries,

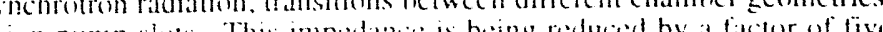
and dis trithe 政

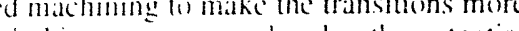
gradual and the ion pump slos narrower. With this new vactum chamber the potential well distortion and microwave instahility thresholds will be well above the charge that

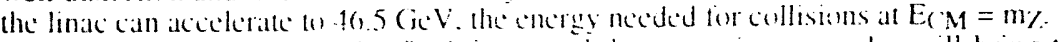

It is projecied that the final focus and dampung ring upgades will hring the

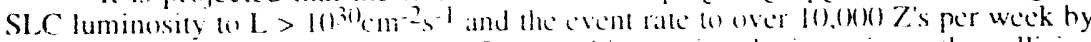
decreasing the vertical sig $10 \sigma_{5} \leq 0.5 \mu m$ and increasing the intensity at the collision poine to $35-4 \times 10110$ It is diflicult to predict paramelers and perlormance precisely

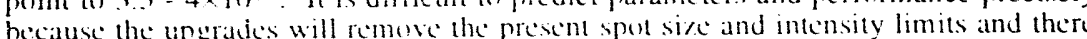
hecause ise une that should increase the lominosily by roughly $30 \%$

A wide range of knowledge has heen leaned from the Sl.C. It can be characterised as:

1.- The development of particular components or systems that were pushing the state of -the-art and are now the standard for comparison and the hase for the nex developments. Examples are the a) MW klystrons, the positron target and capture system. and the polariad electom gem.

2- Techniques that inate proven their value in SLC operation and have heen

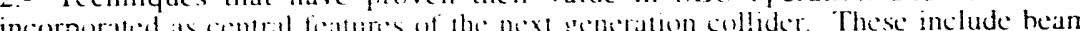
hased alignment and optics diagnestics. lechnigues for emittance preservation, and

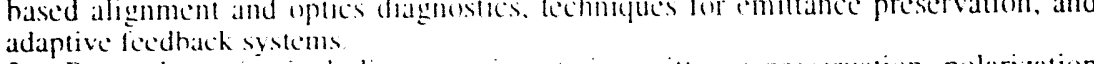

3.- Beam dynamics including experiments in emillance preservation. polariation control, and damping ring heam instathilates. The anticipated observation of disruption next year will be ahe first expertence with bean-heam effects in linear colliders.
4.- Design philosophese for future colliders. Lincar collders are complex, and that complexity is hound to increase with incerasing energy. The interdependence of the SLC accelerator systems made commissioning difficult, and it still shows up today in subte ways such as trips of the SLD drift chamber high voltage heing the first, most evident manifestation of the damping ring microwave instability. Reliability and quality assurance (OA) have unfortunate, hureaucratis connotations, but specifying reliahility and treatine it on a par with perturmance and coss would have decreased the

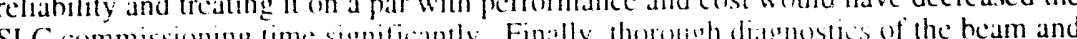

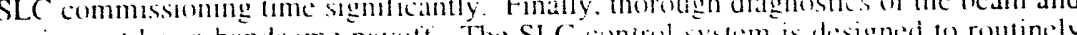
equipmem has a handsome payoli. The SLe conch measure and log an ciontmous amount of data such as hedm cmitances, power supply control and readhack signals. and lemperatures in all parts of the accelerator. These data are invaluable for finding and fixing prothems which oflen are not evident when they tirst occur

$\mathrm{ECM}=0.5 \mathrm{THE} / 1$

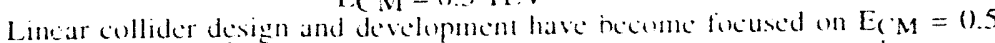

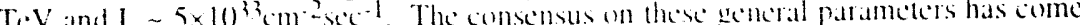
TeV and 2 se athe beciuse they com meludte sectics

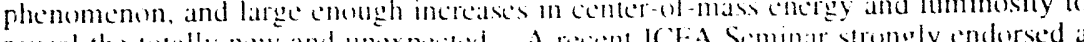
reveal the lotally new and tmexpected. A recent ICFA Semmat strongly condersed a 0.5 TeV linear collider as the next natural step for high encry physics after the L.HC

There are diverse approaches 10 mecting the se eneral whicelives. The diversity arises from diflerent judgments about the case of developng new and improving existing technolugy, costs, extension to higher encrgies. experimental hackerounds, center-ol-mass crieryy spectrum, wherences, and beam power.

Selected parameters are given in Table III which is based wil a compilation made hy (i.

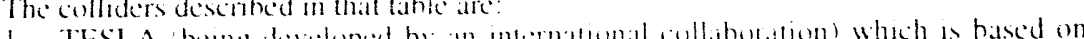

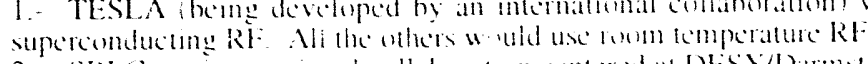

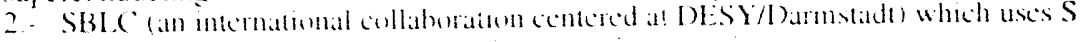

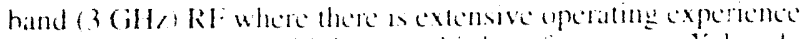

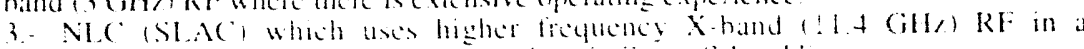
modulator-klystron-atceletater contiguration smilar wo S-hand linac.

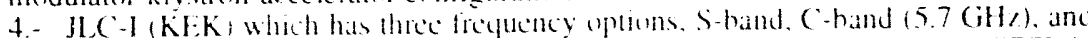
$X$-hand Multiple humbes are acceleraled in each RF pulse ats they are in TESLA. SBLC, and NLC

5. VLEPP (NP) which cmploves a single high mlensity hunch rather than multiple bunches.

6. CLIC (CERN) which is a "fo-heam" accelerater with klvstrons replaced hy an RF power source based on a high-curent. low-energy beam traveling parallel to the high energy he:am.

The Ac powe: is large for any of the colliders, and energy chliciency is important. (ne way to achicke good effictency is by acceleralung multiple hean hunche's per RF pulse.

For exumple in the SBLC i $150 \mathrm{MWW} 28 \mu \mathrm{sec}$ long RF pulse powers two $6 \mathrm{~m}$ long section:; to d gradicnt if $17 \mathrm{MV} / \mathrm{m}$. The heam has 125 hunches with $2.9 \times 10^{10}$ 
Table III Selected Linear Collider Parameters for $E_{C M}=11.5 \mathrm{TeV}$ G. Locw, L(93) 13

\begin{tabular}{|c|c|c|c|c|c|c|c|c|}
\hline Parameter & TESLA & SBLC & $\begin{array}{c}\text { JLC-I } \\
\text { (S) }\end{array}$ & $\begin{array}{c}\text { JLC-I } \\
\text { (C) }\end{array}$ & $\begin{array}{l}\text { JLC-I } \\
(X)\end{array}$ & NLC & VLEPP & CLIC \\
\hline $\begin{array}{l}\mathrm{L} \\
\left(10^{33} \mathrm{~cm}^{-2} \mathrm{~s}^{-1}\right)\end{array}$ & 7 & 4 & 4 & 7 & 6 & 8 & 15 & $2-9$ \\
\hline RF Freq $(\mathrm{GHz})$ & 1.3 & 3.0 & 2.8 & 5.7 & 11.4 & 11.4 & 14 & 30 \\
\hline Rep Kate (Hz) & 10 & 50 & 50 & $I(x)$ & 150 & 186 & $3(0)$ & 1700 \\
\hline $\begin{array}{l}\text { Bunches per } \\
\text { RF pulse }\end{array}$ & $8(K)$ & 125 & 55 & 72 & 90 & (4) & 1 & $1-4$ \\
\hline $\mathbf{N}\left(10^{10}\right)$ & 5.15 & 219 & 1.30 & 1.1 & 0.63 & 0.65 & 20. & 0.6 \\
\hline $\begin{array}{l}\text { BPM Precision } \\
(\mu \mathrm{m}) \dagger\end{array}$ & 10 & 10 & $\mathrm{NA}$ & $\mathrm{NA}$ & 1 & 1 & 0.1 & 0.1 \\
\hline $\begin{array}{l}\gamma_{x} y^{\prime} \varepsilon_{y} \\
\left(10^{-8} \mathrm{~m}\right)\end{array}$ & $206(x) / 100$ & $10(x) / 50$ & $330 / 4.5$ & $330 / 4.5$ & $330 / 45$ & $5(k) / 5$ & $2(W 6175$ & $180 / 20$ \\
\hline$\beta_{x}^{*} \beta_{y}^{*}(m n)$ & $25 / 2$ & 22011.8 & $10 /(1) 1$ & $10 \% 0.1$ & $10 / 11.1$ & $10 /(0.1$ & $1(k) /() .1$ & $2.2 / .16$ \\
\hline$\sigma_{x}\left(1 \sigma_{y y}(\mathrm{~nm})\right.$ & $1(0 K) / 6-t$ & $670 / 28$ & $3(16) / 3$ & $2611 / 3$ & $26(1 / 3$ & $30(0) / 3$ & $20 k 6) / 4$ & $90 / 8$ \\
\hline$\sigma_{\mathbf{L}}(\mu \mathrm{m})$ & $\operatorname{li}(x)$ & $5(k)$ & 80 & 80 & 67 & 100 & 750 & 170 \\
\hline $\begin{array}{l}\text { IP Crossing } \\
\text { Angle (mriad) }\end{array}$ & 0 & 3 & 7.3 & 8 & 7.2 & 3 & $\cdots$ & 1 \\
\hline$Y$ & 01021 & 0.1155 & 0.24 & 0.21 & 0.16 & $0.16 \%$ & 0.074 & 11.35 \\
\hline$H_{D}$ & 23 & 16 & 16 & 1.5 & 17 & 1.4 & 1.3 & 3.3 \\
\hline$\delta_{\mathbf{B}}$ & 0.13 & 003 & (1).10 & 0.08 & 0.05 & 0.03 & 0.13 & 0.36 \\
\hline $\mathbf{n}_{\gamma}$ & 27 & 20 & 16 & 14 & 10 & .9 & 5.0 & 4.7 \\
\hline $\begin{array}{l}\text { Loaded Grad. } \\
\text { (MV/m) }\end{array}$ & 25 & 17 & 19 & 33 & 31 & 38 & 96 & $78-73$ \\
\hline $\begin{array}{l}\text { Two Linac } \\
\text { Length (km) }\end{array}$ & 20) & 20.4 & 28 & 16.7 & 17.7 & 14 & 6.4 & 6.6 \\
\hline $\begin{array}{l}\text { Section Length } \\
\text { (m) }\end{array}$ & 1.14 & 6 & 3.6 & 2 & 1.3 & 1.8 & 1.01 & 0.273 \\
\hline $\begin{array}{l}\text { Number of } \\
\text { Sections }\end{array}$ & 111232 & 4900 & 7776 & 8360 & $13(k)$ & 7778 & 5200 & $24(00)$ \\
\hline $\begin{array}{l}\text { Number of } \\
\text { Klystrons }\end{array}$ & 1202 & 2450 & $194+4$ & $41 \times 0$ & $34(x)$ & 1945 & $13(k)$ & 2 \\
\hline $\begin{array}{l}\text { Klystron Peak } \\
\text { Power (MW) }\end{array}$ & 3.25 & 150 & 85 & +5 & 70 & 144 & 150 & 700 \\
\hline 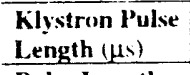 & $13(k)$ & 2.8 & 4.5 & 36 & 0.54 & 1.5 & 0.7 & 0.011 \\
\hline $\begin{array}{l}\text { Pulse Length } \\
\text { to Section ( } \mu \mathrm{s})\end{array}$ & $13(1) 0$ & 2.8 & 1.2 & 0.6 & 0.21 & 0.25 & $0.1:$ & 0.011 \\
\hline $\begin{array}{l}\text { Pulse Comp- } \\
\text { ression Gain }\end{array}$ & -. & $-\cdot$ & 2.4 & 4.2 & 3.2 & 4 & 4.22 & -- \\
\hline $\begin{array}{l}\text { a/ (input } \\
\text { output calvily) }\end{array}$ & 0.15 & $. 1 5 \longdiv { 1 1 }$ & 0.13 & $16 / 12$ & 24.14 & $22 / 15$ & .14 & .2 \\
\hline P'B (MN) & 16.5 & 7.3 & 14 & 24 & 34 & +2 & 2.1 & $4 \longdiv { 1 . 6 }$ \\
\hline $\begin{array}{l}\text { AC Power } \\
\text { (MW) }\end{array}$ & 137 & 114 & $l k$ & 193 & $\mathrm{So}_{0}$ & 141 & 91 & 175 \\
\hline $2 P^{2}{ }_{B} / P_{A C}$ & 1124 & 0.13 & 0.03 & 0.14 & $0(0)$ & 010 & 0.105 & 0.12 .2 \\
\hline
\end{tabular}

Addition to G Lecwescompilation (from Rel. lf) particles per hunch spaced 16 new anart The RF pulse has $420 \mathrm{~J}$ of energy; a single hunch extracts $(1.95 \mathrm{~J}$ from the accelerator RF fiedds, and the hunch train extracts a total of $118 \mathrm{~J}$ leading to an efficiency, $\eta_{B}$, for converting $R F$ to heam energy of $\eta_{B}=$ 0.28 . If only a single bunch was accelerated. the RF pulse could be shortened to $\mu$ sec, the accelerator filling time, hut the efficiency would be low. $\eta_{B}=0.006$. A major advantage of multiple hunches is that the cost of tilling the accelerator with RF energy has hew amortiged over a large number of bunches.

Multiple hun tes hwe implications for both the fundamental and higher modes. The energy spread of the beam must be small to minimize emittance blow-up modes. The energy spread or the heame from dispersive eflects in the linac ando mine me structure must be prefilled and the $\mathrm{RF}$ amplitude ramped so that each bunch gains the same energy.

The bunches are closely spaced, and they interact through higher modes. The transverse modes can cause emittance blow-up that is in addition to that from the shor range transverse wakefield. The interaction helween bunches must he reduced hy damping higher order modes or by detuning, varying cell dimensions to spread mode

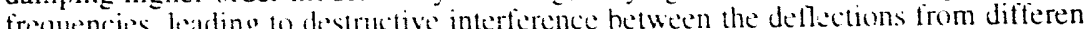
frey 16 Detuning and damping ma have wo he combined we get adeyuate reduction of the long range wakefields.

the long range wakefields. 0.12 The lor hunch and on the linare for and and relatively high RF frequency focus, where a head-til enerey shift is introduced os shift the focal point during the collision and prevent enormous disruption. CLIC has parameters tor hetween one and four hunches. and studies of energy compensation and transwerse modes for four bunches are in progress. ${ }^{17}$

Present day. conventional linacs are modular with cach module consisting of a

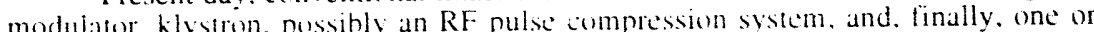
more acceleratur sectons pouced in parailel. The modulator converts AC power to high voltage, pulsed power. Most use a low voltage. lumped eler on transmission line for energy storage, thyratrons as switches, and a pulse transformer wo step-up the output voltage. SLAC modulators are typical and are roughly $75 \%$ efficient. ${ }^{8}$ A substantial fraction of the inefficiency comes from the risc-and fall-times of the pulse transformer. Improving modulator efficiency would be significant. A capacitor bank and high voliage switch whe rather than is pulse transformer was hemg considered for the SBLC but has be the SBLC, hut has bect

A short high nower RF pulse is the ideal for high trequencies hecause short sections and high groun velocities are favored by efficiency and wakefields. The input nower mus be multiplied hy $\tau^{2} /\left(1-\tau^{-2} \tau^{2}\right.$ for the same average accelerating gladient : $\tau$ power must be multiplic hy $\tau-2$ tion length $B$, is the (normalied group velocity. and $\lambda$ is the RF wavelength is The waveiength dependence comes from the skin effect. The maximum transverse wakefield hehaves as $1 /\left(a^{3}(\lambda / a)^{8}\right)$ ) where a is the radius of the waveguide iris 20 Increasing 1/a reduces the wakefield with the side effect of raising the group velocity. ${ }^{19}$

It is impractical of generate short RF pulses cirectly. Modulator efficiency would be poor hecause pulse rise-and fall-times would be a large fraction of the pulse wa ke poor hak power would be enurmous. Pulse compression ${ }^{21}$ which raises the peak power while shortening the RF pulse is used for matching klystron cupahilities to 
an optimum accelerator configuration and is a cature of the high RF frequency colliders.

TESLA has unique power source requirements. The high $Q$ and long pulse length reduce the peak power to $3.25 \mathrm{MW}$, hut the modulator must be capable of delivering that power for over a millisicond.

All excent CLIC have a large number of klystrons. CLIC is a two-beam accelerator which replaces all of this with a single. low-energy heam traveling paralle to the high energy heam. This luw-inergy heam has a time structure appropriate for generating $30 \mathrm{GH}$ / RF. It is accelerated by a superconducting RF system, and energy is extracted with transfer structures spaced roughly $1.5 \mathrm{~m}$ apart.

The vertical invariant emittances, $\varepsilon_{y}$. are small, and emittance preservation during acceleration is an important consideration. Emittance growth caused by the combination of injection itter and wakefields must be controlled hy tight tolerances on injection elements and B.VS damping. 22 Those wlerances range thom about $1 \mu \mathrm{m}$ for NLC and JLC-I(X) lo ahout $10 \mu m$ for the S-hand accelerators and TESLA. ${ }^{14}$

Misalignments in the main linac cause emittance growth through wakefields and dispersion. With stranght one-to-une orhit correction, i. e. steering to the middle of . beam position monitors. there would he extremely as examples, those tolerances quadrupole, and heam position monter alignment. As

Beam-based orbit correcion procedures, where optical elements are varied and orhit changes measured. relieve these lukerances substantially. ${ }^{4}$ The strengths of all the quadrupoles are increased, or decreased. in Dispersion Free (DF) steering to measure momentum dependence of the central trajectory: then. the arhit is corrected to minimize the dispersion. The strengths of focusing yuadrupoles are reduced while those of defocuing quadrupules are rised a dproximate the defocusing effect of

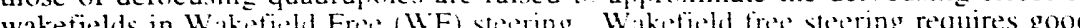
(ance these procedures depend on measuring orhit changes. the heam postion monitors (BPM's) must be precise. Estimates of the required precisions are included in Tahle III and range from $0.1 \mu \mathrm{m}$ for CLIC and VLEPP $1010 \mu \mathrm{m}$ for SBLC and TESLA. ${ }^{1+}$

The heams are tlat at the meraction point to minimize hackgrounds (see below) with $\gamma \varepsilon_{x} \gg \gamma \varepsilon_{y}$ and $\beta_{x}{ }^{*}>\beta_{*}{ }^{*}>\sigma_{I}$ (for all but VLEPP with its traveling focus) where $\sigma_{I}$ is the hunch length. The vertical dimension is the most demanding with the vertical sices before disuption rarieing from ot $\mathrm{nm}$ (TESLA) $103 \mathrm{~nm}$ (JLC NLC).

The vertical spot sises qunted are the first order sizes $\sigma_{y 0}=\left(\beta_{y}{ }^{*} \varepsilon_{y}\right)^{1 / 2}$, and up to third order reametric and chromatic sherrations mus he corrected to reach those sizes. This is done by using dipoles to introduce dispersion in a region with sextupoles sizes. This is done by using dipoles to introduce dispersion in a region with sextupoles separated by a -1 tansformatton. Synchrotron radiation losses in the chrom

There are extremely tight pulse-to-pulse jitter tolerances. For all but the finat doublet those colerances are ahout $111 \sigma_{y}$ while for the final doublet they are roughly $\sigma_{y}{ }^{23}$ The Final Focus Test Beam (FFTB) at SLAC will test many of the techniques for reducing aberrations to the re uired kevel and will provide a test bed for studying and specifying jitter wlerances.

The heams cross at an angle. This aroids unwanted collisions for colliders with closely spaced bunches, and it allows the channel for ficusing the incoming beam to he independent of the channel for the exiting disupted heam. Crab crossing. ${ }^{24}$ tilting the bunches with an RF deffector. prevents luminosity loss due to incomplete overlap.

The luminosity is given by

$$
\mathrm{L}=\frac{\mathrm{N}^{2} \hat{\mathrm{f}}_{\mathrm{c}}}{4 \pi \sigma_{\mathrm{x} 0} \sigma_{y(0)}} \mathrm{H}_{\mathrm{D}}=\frac{\mathrm{N}^{2} \hat{\mathrm{i}}_{\mathrm{c}}}{4 \pi \sigma_{\mathrm{x}} \sigma_{\mathrm{y}}}
$$

$\mathrm{N}$ is the number of particles/bunch and $\mathrm{f}_{\mathrm{C}}$ is the collision frequenc?. Focusing during the collision, discuption, is accounted for by an enhancement fact or. $\mathrm{H}_{\mathrm{I}}$, in the letthand expression where the heams sizes without disruption are used, and by asing the discupted beam sizes in the right-hand expression.

The electromagnetic liclds at the collision point: : parametrized by 25

$$
Y=\frac{5 r^{2}}{6 \alpha} \frac{\gamma N}{\sigma_{\mathrm{L}}\left(\sigma_{\mathrm{x}}+\sigma_{y}\right)}
$$

Field enhancement due to disruption is accounce for approximately by using the disrupted sizes This increases Y for TESLA. SBLC. and CLIC because the horizont size is redued ahout $50 \%$ hy discuption in those be pairs, and hadronic crents depend on $Y$. When $Y \ll<1$ and $\sigma_{x} \gg \sigma_{y}$, the mean number pairs, and hadronic events depend on $Y$. When $Y \ll<$

$$
\mathrm{n}_{\gamma} \cong \frac{5 \alpha^{2} \sigma_{\mathrm{L}}}{2 \mathrm{r}_{\mathrm{e} \gamma}} \mathrm{Y} \cong \frac{2 \alpha \mathrm{r}_{\mathrm{L}} \mathrm{N}}{\sigma_{\mathrm{x}}}
$$

This parameier serves as an approximate measure of hackground.

The luminosity can he rewritten in terms of only three frec parameters: $n_{\gamma}, \sigma_{y}$. and the heam power. $\mathrm{P}_{\mathrm{B}}=\mathrm{N} \gamma \mathrm{m} \cdot \mathrm{I}^{2} \mathrm{C}$

$$
L \equiv \frac{1}{8 \pi \alpha r_{c} m^{2}} \frac{P_{B} n_{\gamma}}{\gamma \sigma_{y}}
$$

The diversity of approaches in Table IIl arises from different judgments about the following.

The ease of de'teloping new and improning existing itchology - SBLC and JLC-l(S) are the most conservative in this regard. They take udvantage of over forty years of experience with S-hand RF. NLC. JLC-l(C), and JLC-I $(X)$ evend the basis of present day linace, high peak power klystrons and modulaturs, to higher frequencies Klystrons and accelerator structures must be deseloped for those frequencis. TESL A lolics acterating requencies. TESLA retich RF VLEPP requics innovations to meet demanding gradent of superonductung RF. LEPP requires innowations to meet demanding tolerances and reles on novel heam dynamics in the linac and hinal focus. CLIC has stringent tolerances because of its high fiequency, and the RF power source development by it of other colliders.

Costs - Cost reduction and cost control must he dominant considerations as designs are developed. New technologies promise significant, hut uncertan. cost reductions. Older wethnolugies have heller established custs, hut these tend to be high and must be lowered hrough engineering and mas production. The experience of the SSC an accelerator hased on mature lechnology and d detailed design. teaches us that present linear collider cost estimates should not he taken seriously.

Extension to higher entergies - An $\mathrm{E}_{(\mathrm{N}}=0.5 \mathrm{TeV}$ collider should be a step towards multi-TeV energies. High gradients and high RF frequencies tend to be hetier 
for reaching high energies with room temperature RF. NLC. JLC-I(X), and VLEPP are optimized for $0.5-1$ TeV while it would be difficult w directly extend S-hand colliders heyond $0.5-1 \mathrm{TeV}$. CLIC is a multi-TeV collider scaled down to $0.5 \mathrm{TeV}$ for purposes of comparison. The energy reach of TESLA depends on how :luse the fundamental gradient limit of $-50 \mathrm{MV} / \mathrm{m}$ in $\mathrm{Nh}$ can he approached. This issue of extension to higher energies is discussed more in the next section.

Experimental backgrounds and center-of-mass energy spread-The effects of beamstrablung have been cantured in ey. (7) with a single narameter, $\mathrm{n}_{\gamma}$. This parameter doesn't account for the eneroy spectro of photons, $\mathrm{e}^{+} \mathrm{e}^{-}$pairs, and hadronic parame and it doesn't account for the overlap of events in the detector. The the number, and it is only through the onguing sludies of that intertace that tolerable hackground levels can he estimated

Tolerances and beam power - The trade-olf is given in eq. (7). Increasing the beam power relaxes injection tolerances, heam position monitor precision, and pulseto-pulse jitter in the final focus hy allowing a larger $\sigma_{y}$. However, there are limits to beam power from efficiency and heam handling, collimation and accelerator protection.

Prototypes addressing heam dynamics and engineering will help narrow the range of choices. The:se prototypes include:

1. A $5(x)$ MeV TESL A protolype w he constructed at DESY to demonstrate a gradient of $15 \mathrm{MV} / \mathrm{m}$. (1) mect cost geals. and to lest a high gradicnt superconducting linac with beam

2.- A 450 M.V SBLC protulype that will kest long pulse, high power, multiple hunch operation of an $S$-hand linac.

3.- The Accelerater Test Facility at KEK that combines a $1.5 \mathrm{GcV}$, S-hand linac with a prototyne damping ring. The damping ring will produce heams with brightness,

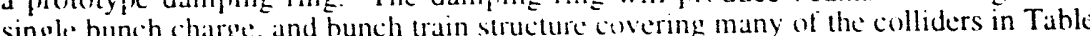
III New hevels of alerances, countol of heam gencrated lields, extraction kicker stability, etc. will be reached in accomplishing this.

stability, etc. Will he reched in acempling hocus Test Beam 4.- Interaction region uptics and stability will be studied at the Final Focus Test Beam at SLAC. In addition, strong field QED, the regime of heamstrahlung in high energy
linear colliders, will be explored experimentally.

5.- A 540 A.NV prototype NLC linat has the govals of constructing, weliahly operating. and studying beam dynamics in an $X$-hand lina

6.- A $-5(x) \mathrm{MeV}$ VLEPP prototype wall lest the klysirons, accelcrator, and beam dynamics of that collider.

7.- A heam with the time sructure of the CLIC drive heam will he generated by an 7.- A beam with the time stan ace Facility

The lessons kearned from continuing uperation of the SLC and the answers to some broader yuestions will contribute as much as or more than these prototypes to determining the hest approach for the next generation linear collider.

THREE ISSL HSS FOR THEFLTLRE

There has bere a thane in the consederations that have dominated linear

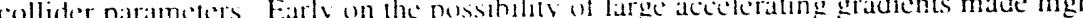

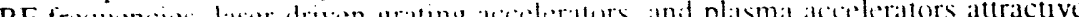
Enerey eflicincy and hem sumics have become more important now as the heam requirements and operating costs have hecome hetter understond. Complexity is a major factor that is still not heing given the attention reyuired. An assumption underlying the range of parameters in Tahle lil is that each of colliders would be equally operabic. There is no redson to believe this.

For example the number of klystrons for the conventional, room temperature colliders in Table ill (SBLC, JLC-1, and NLC), range's from 1944 to 4180 ). Each klystron and its associated modulator is a major piece of equipment The factor of two klystron an the difference between a range in the number of klyster coilider that can be commissioned rapidy and will run reliably and one that will hot Of course, more than just the number of klystrons is inved in assesting the properties of the components themselves are as important. The principles of reliahility engineering and Quality Assurance need to he used to estamate the reyuired reliability and provide a scien

Altention is focused on $\mathrm{E}_{\mathrm{C}} \mathrm{M}=1.5 \mathrm{TeV}$ for the next collider. Reaching much higher energies is one of the aspirations of the linear collider community, and one higher enerese an intermediate reason for suppore prototype for a higher energy collider. Therefore, it inporte different questions.

First, can a particular collider reach higher energies". There are ideas for exiending the energy of all of the colliders in Table III un to $E_{C M}=1 \mathrm{~T}$. V. Tahle IV gives parameters for three of them. The energy is increased by either: 1) keeping the length the same and increasing the peak power to the linac hy al factor of four the reby doubling the gradient: or 2) doubling the length of the linale. At (1.5 TeV the trade-off hetween beam power and spot size in ey. (7) was exploited hy TESL.A and SBLC to increase the verticat ano sios hy increasing the heam pouse That trade-oft is not increase he verical s. TeV. Evaryon is relying on small spots to make luminosity.

Second, can an approach be extended to substantially higher energies, Say ECM heyond the SLC too much will be leamed hetween mow and then. Trends are clear, however: low heam power and small spots is the direction meeded for multi-TeV colliders. The two different approuches to huilding a $10.5 \mathrm{TeV}$, superconducting RF and room temperature RF. have different outlows fior $2 \cdot 5 \mathrm{TeV}$.

The advantare of superconducting $R F$ at $E_{C M}=0.5 \mathrm{TeV}$ is the ahility to tradeoff heam power and spot sige hul that advantage has largely gone away hy 1 TeV.

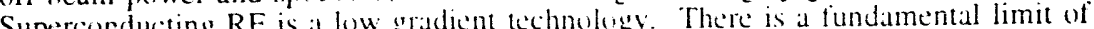
Supere $\mathrm{M}$ V/m that come

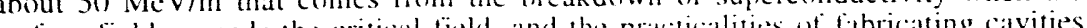

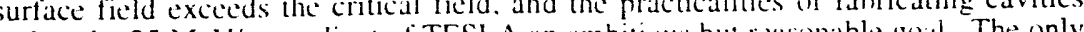
makes the $25 \mathrm{Mc} / \mathrm{m}$ gradient ol TESLA an ambitions hut rear way to extend the energy is to extend the length. A pucking lactor of $71 \%$... hoped for, and the $\mathrm{E}_{\mathrm{C}} \mathrm{M}=1 \mathrm{TeV}$ accelerator is close to $55 \mathrm{~km}$ long for an active length of 40 $\mathrm{km}$. The superconducting approach is not likely to take one far beyond $\mathrm{E}_{\mathrm{C}} \mathrm{M}=0.5$ TeV.

There is a factor of ten in the RF frequencies of the room temperature colliders in Table III, but there are many considerations in common including: multiple bunch energy control and higher mode damping and detuning needed for multiple bunches; precision beam position monitors alienment and steering alorithms needed for 作

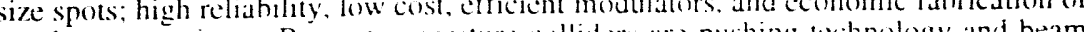
accelerator sections. Room temperature enllow ane pushing dynamies in the difections needed for multi-Tev cenllsions. In addition, the room temperature RF approach does not have a fundamental gradient limit forcing one to 
Tahle IV Comparison of Linear Collider Parameters for ECM $=0.5 \mathrm{~T} \cdot \mathrm{V}$ and $\mathrm{ECM}=10 \mathrm{~T}$.

\begin{tabular}{|c|c|c|c|c|c|c|}
\hline Parameter & $\overline{\mathrm{TE}}$ & & & & & \\
\hline $\mathbf{E}_{\mathrm{CM}}(\mathrm{TeV})$ & 0.5 & 10 & 0.5 & 1.0 & 01.5 & 1.0 \\
\hline L $\left(10^{33} \mathrm{~cm}^{-2} \mathrm{~s}^{-1}\right)$ & 7 & !) & 4 & 6 & 8 & 20 \\
\hline Rep Rate $(\mathrm{Hz})$ & 10 & 5 & 50 & 50 & 180 & 120 \\
\hline Bunches/KF pulse & 800 & 4180 & 125 & 50 & 90 & 67 \\
\hline$N\left(10^{10}\right)$ & 5.15 & $0.9 !$ & 2.9 & 2.9 & 0.65 & 1.3 \\
\hline$\left.\varepsilon_{\mathbf{X}} / \gamma_{\mathbf{y}}(10)^{-\gamma_{m}}\right)$ & $2(x)(0 / 1(x)$ & $521 / 3.3$ & $10(\%) / 50$ & $1(x)(x) / 10$ & $500 / 5$ & $500 / 5$ \\
\hline$\beta_{\mathbf{x}}{ }^{*} \beta_{\mathrm{y}}{ }^{*}(\mathrm{~mm})$ & $25 / 2$ & $2(\pi$ & $22 /(1.8$ & $32 / 10.8$ & $16 / 0.1$ & $40 / 0.1$ \\
\hline$\sigma_{x(y}\left(v \sigma_{y}\right)(\mathrm{nm})$ & $1(k n) / 6+$ & $325 / 8$ & $670 ; 28$ & $572 / 9$ & $3(0) / 3$ & $425 / 2$ \\
\hline$\sigma_{L}(\mu m)$ & $1(k)$ & $50)$ & $5(x)$ & $5(h)$ & $1(x)$ & 100 \\
\hline $\mathrm{Y}$ & (1). (12) & $0.05 x$ & 01.055 & $0 .\left(x^{2}\right) 1$ & (1) $(k) 6$ & 0.28 \\
\hline $\mathrm{H}_{\mathrm{D}}$ & 23 & 20 & 1.0 & 1.7 & 14 & 1.6 \\
\hline$\delta_{\mathbf{B}}$ & 10.13 & 0.013 & 0.03 & (1). 017 & 0013 & 0.08 \\
\hline $\mathbf{n} y$ & 27 & 13 & 20 & 23 & 0.9 & 1.1 \\
\hline Load Grad.MN/m) & 25 & 25 & 17 & 34 & 38 & 76 \\
\hline Linat length (km) & 211 & 4) & 29.4 & 29.4 & 14 & 14 \\
\hline Number of klystrons & 12112 & 2414 & 2450 & 4000 & 1945 & $38 \% 0$ \\
\hline Klystr Pk Pur inW & 325 & 325 & 150 & 150 & 94 & 188 \\
\hline Pulse Comp. Ciain & $\cdot \cdot$ & $\cdots$ & $\therefore$ & 2 & 4 & 4 \\
\hline$P_{B}(M I W)$ & 105 & 152 & 7.3 & 58 & 4.2 & 8.0 \\
\hline AC Power (MW) & 1.37 & 154 & 114 & 2010 & $1+1$ & 280 \\
\hline $2 P_{B} / P_{A C}$ & 1924 & 0.11 & 11.13 & 0.06 & 0.06 & 0.06 \\
\hline
\end{tabular}

The $\mathrm{E}_{\mathrm{CM}}=0.5 \mathrm{TeV}$ parameters are from $\mathrm{G}$. Loew, ${ }^{13}$ and the $\mathrm{E}_{\mathrm{CM}}=1.0 \mathrm{TeV}$ parameters from B. Wiik. 26

increase length to reach high energies. A room temperature, $E_{(M)}=0.5 \mathrm{TeV}$ collider has promise as an intermediate protulype for multi-TeV collisions.

There is world wide interest in huilding a large linear collider. and the interested parties have formed technical and scientific collaborations to that end. TESLA and the FFTB are two broad hased, international collaborations pursuing linear collider development, and many of the other prototypes have participation outside of the home lahoratory. The LC (Lincar Collider) series of workshops has heen a forum for accelcrater phssics discussions. and the workshops on Physics and a bave played a similar role for the

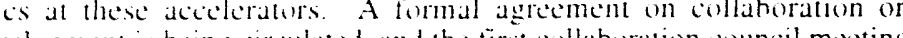
acclerator develoment is heine circulated. and the first collahoration council meeting should be in Junc. lyyt.

A politicil mechanism for the support of a large linear collider is needed in addition to these scientist-lo-scientist and lahoratory-to-lahoratory collaborations. Large fusion. space research, and high energy physics collaborations will set precedents for this. The former Director of the Oftice of Energy Research. William Happer has commented on large scale high energy physics projects in the light of what is hapening with ITER. the International Thermonuclear Experimental
Reactor. 27 Cost sharing and the difficulty of negating a treaty are important advantages of an international agreement for a large science project, but there are associated prohlems and costs. These include the dificulty of chowsing a site the time scale for formal deliberate nerotiations. and constituencies in the coremment that favor a slow time scale.

The biggest uncertainty we face is in the political arena.

\section{ACKNOWLEDGEMENTS}

Greg Loew has kindly let me reproduce his table of parameters from LC-9 (Tahle III). I have henelited from stimulating discussions ahout future linear collider with Dave Burke, Pisin Chen, John Irwin, Bob Palmer. Tor Raubenheimer, and Ron Ruth. Finally, thanks to my SLC colleagues. It is an exciting accelerator to work on and a wonderful groun of peonle to work with.

\section{REFERENCES}

1. LEP Design Renort. CERN LEPR

G. Bachy et al. Particle Accelerators 26. $19(1990)$

M. Tigner, Nunvo Cimento 37. 1228 (1965)

Table 9.2.4.1 in SLC Design Handhook (SLAC. Dec 1984t

C. Adolphsen et al. Proc nl 1993 Part Aciol Cont. SL.AC-PL B-6255

C. Adolphien e't al, Pric of 1993 Part Acciel Cont. SLAC-PLB-6118

N. J. Walker $e^{\prime} t$ al. Proc of 19y3 Parl Aciol Cont. SLAC-PUB-62)t.

K. Ahe et al. Phys Rev Lell 70. 2515 (1993).

9. C. E Adolnhsen ét al 1991 IEEE Particle Acolerator Conference 503 (1991).

io. P Krejcik et al Proce of l993 Part Accol Cont SLAC-PLB-6230.

11. This section is an update of R. H. Sicmam, "Overview of Lincar Collider Designs". Proc of 1993 Part Accel Cont. SLAC-PUB-6244

12. ICFA Seminar held at DESY. May. 1993

13. Greg Loew. pritate communication. Proc of LCO3

14. T. Raubenheimer. Proc of 1993 Part Accel Coni. SLAC-PU B-6117

15. K. A. Thempson and R. D. Ruth. Proc of J993 Part Accel Cont SLAC-PUB-6154.

16. K. A. Thumpson, C. Aduphoen and K. L. F. Bame. Proce of l993 Pan Accel Cont. SLAC-PLB-6153.

17. I. Wilson and W. Wuensch, Proce of the 1993 Pant Accel Cont, CERN-SL/93-20.

18. P. Wilson, privatic communication

19. Z. D. Farkas and P. B. Wilson. 1987 IEEE Particle Accelerator Cont. 1561 (1987).

20. P. B. Wilson. SLAC-PLB-3674 (1985)

1. P. B. Wilson. Z. D. Furkus and R. D. Ruth. SLAC AP-78 (1999).

22. V. Balakin. A. Nowokhatski and V. Smimov, Prox of 12 ih Int Cont on High Energy Accel, $119(1983)$

23. J. Irwin, private communication.

4. R. B. Palmer Proc DPF Summer Study Snowmass 88, n. $613(1988)$

5. Pisin Chen, Photon-Pholon Collisions 41811992

36. Wiik. presintation to LCO3. Proc of LCy

27. William Happer. AIP Conf Proc 272 (Prex XVI Inter Cont on High Energy Physies) xxxvii (1993). 

